\title{
¿Civilización o barbarie? Imaginaciones espaciales rizomáticas y abismales de Europa y Latinoamérica en la obra de Roberto Bolaño
}

\section{Civilisation or barbarism? Rhizomatic and abyssal spatial imaginations of Europe and Latin America in Roberto Bolaño's work}

\author{
MACARENA ARECO \\ Centro de Estudios de Literatura Chilena, CELICH \\ Pontifica Universidad Católica de Chile. Correo electrónico: mareco@uc.cl
}

El objetivo de este artículo es mostrar algunas figuraciones imaginarias del espacio que se reiteran en las obras de Roberto Bolaño. Por una parte, el territorio europeo, que es descrito como un rizoma y opera como una línea de fuga que protege, en cierto sentido, al migrante latinoamericano, tal como aparece en Los detectives salvajes (1998), El Tercer Reich (2010) y Los sinsabores del verdadero policía (2011). Por la otra, el infierno y el abismo como cifras del subcontinente representado por Ciudad Juárez, la Santa Teresa de 2666 (2004), en donde la violencia se enseñorea y los sujetos son destruidos en el marco del tercer estadio del capitalismo, globalizado e informatizado.

Palabras clave: civilización, barbarie, imaginario social, espacio, rizoma, infierno, violencia

The objective of this article is to show some reiterated imaginary figurations of space in Roberto Bolaño's works. On the one hand, the European territory, which is described as a rhizome and operates as a line of flight that protects, in a sense, the Latin American migrant, as it appears in Los detectives salvajes (1998), El Tercer Reich (2010) and Los sinsabores del verdadero policia (2011). On the other hand, hell and the abyss as figures of the subcontinent represented by Ciudad Juárez, 2666s Santa Teresa (2004), where violence dominates and subjects are destroyed within the framework of capitalism's third stage, global and digital.

Key words: civilisation, barbarism, social imaginary, spaces, rhizome, hell, violence 
"Escribir no tiene nada que ver con significar, sino con deslindar, cartografiar, incluso futuros parajes"

(Deleuze y Guattari, Rizoma).

En la etapa fundacional de las naciones latinoamericanas, la dicotomía civilización y barbarie se establece como una figuración imaginaria básica acerca de nuestro territorio, que se expresa repetidamente en la literatura y en la política de los dos siglos posteriores, alimentando una serie de oposiciones binarias -entre ellas Buenos Aires y la pampa, la capital y el campo, los colonizadores y los indígenas, la industria y la agricultura, los hombres (y mujeres) de la ciudad y los de la selva-, las cuales construyen la realidad ${ }^{1}$. Hacia el exterior, como mirada comparativa y autoevaluativa, Europa se semantiza como la cultura del progreso y la ilustración a la que se aspira, en contraste con el mundo propio entendido como el espacio atávico de la violencia del cual es necesario huir, si se quiere salvar con vida. Como ha explicado Ricardo Piglia en La Argentina en pedazos (1993), en el prólogo de Facundo la cita de Diderot que Sarmiento deja a modo de testimonio en la pared cuando parte hacia el exilio - "On ne tue point les idées"- define a los bárbaros -los seguidores de Rosas, los hombres de la mazorca- como aquellos que se encuentran al margen de la cultura europea, o quienes, dicho sinecdóquicamente, no entienden el francés.

Muy avanzado el siglo XX, la oposición sigue operando, de lo cual son un muy buen ejemplo los cuentos de Julio Cortázar. La burguesía acomodada, versus los "bárbaros" del pueblo peronista, según una de las lecturas posibles de "Casa tomada"; la ciudad moderna y el pasado indígena sacrificial en "La noche boca arriba"; la ciudad luz y la calle Suipacha en "Carta a una señorita de París"; en suma, los lados de allá y de acá en Rayuela, son los dos polos entre los cuales el escritor transita como un equilibrista. La oposición cortazariana entre un mundo cotidiano de dentistas, subte y café ("Del cuento breve y sus alrededores") y el prado donde relincha el unicornio ("El sentimiento de lo fantástico") puede ser leída, por ejemplo, si pensamos en "La noche boca arriba", no como la metáfora surrealista de una

\footnotetext{
1 Este trabajo se sustenta teóricamente en el concepto de imaginario social propuesto por Cornelius Castoriadis, quien lo entiende como "[c] reación incesante, indeterminada y colectiva de imágenes (figuras, formas) que produce realidad” (2007: 12). Estas ideas se complementan con las de Bronislaw Baczko, quien plantea que "[a] lo largo de toda la historia las sociedades se entregan a un trabajo permanente de invención de sus propias representaciones globales como ideas-imágenes por medio de las cuales se dan una identidad, perciben sus divisiones, legitiman su poder, elaboran modelos formativos para sus miembros" (2005: 8). En un sentido similar, Josefina Ludmer se ha referido a la "imaginación pública o fábrica de la realidad" (2010: 11). En particular, en relación con la dicotomía civilización y barbarie, Ricardo Piglia afirma que se trata de un sistema de oposiciones creado por Sarmiento que funciona como una máquina de interpretar, es decir, como fuerzas ficticias que constituyen el mapa de la realidad y programan y deciden el sentido de la historia. Es así como, con esta oposición, el autor de Facundo funda el campo metafórico de las clases dominantes (2000: 48). La discusión crítica sobre esta dicotomía requeriría de un volumen completo, pero se sugiere consultar, además del mencionado texto de Piglia y del clásico libro de Sarmiento, Desencuentros de la modernidad en América Latina de Julio Ramos (1989) y el artículo de Grínor Rojo (2009) sobre "El Sur" de Borges que indico en la bibliografía.
} 
realidad otra, más verdadera y secreta, donde las contradicciones se resuelven, sino como la alegoría del emigrado, a salvo en el primer mundo, que mantiene en su inconsciente la marca del horror, es decir, de la violencia latinoamericana, a la cual termina finalmente siendo sacrificado ${ }^{2}$.

Mucho más ambiguo que el de su admirado Cortázar es, en este respecto, el posicionamiento de Roberto Bolaño, quien, si bien por una parte realiza una defensa casi programática de lo proletario, lo marginal, lo lumpen ${ }^{3}$-que son otros modos de decir lo salvaje-, no deja, por la otra, de representar a Latinoamérica como un territorio infernal, imagen con la que figura lo bárbaro. En este sentido, Amalfitano, personaje de 2666 y también de Los sinsabores del verdadero policía, se presenta como un mediador, en tanto realiza un viaje de ida hacia Europa, desde el espacio peligroso -Chile, Argentina, Brasil-a la proliferante Barcelona de los noventa, y uno de vuelta al averno latinoamericano, con destino final Santa Teresa. Algo similar ocurre con el poeta mexicano Mario Santiago y su trasunto ficcional Ulises Lima, según se relata en el ensayo "Literatura y exilio" y en Los detectives salvajes, respectivamente.

Para reflexionar acerca de estas representaciones, este ensayo se inicia con una contextualización en la oposición sarmientina civilización y barbarie que de alguna manera estará sobrevolando en estas obras, luego se da cuenta de la visión ambigua a que da forma Bolaño en el marco de esta polaridad en el ensayo mencionado, en Amuleto y en Los detectives salvajes, para finalizar refiriendo algunas figuraciones presentes en las obras publicadas después de su muerte. Infierno y rizoma, entonces, como arquitecturas de la cartografía imaginaria bolañana que reconfigura la civilización del otro y nuestras barbaries.

\section{RIZOMAS EUROPEOS}

Si queremos saber, en primer lugar, dónde se ubica Bolaño en relación con la dicotomía, en el inicio del "discurso insufrible" de Entre paréntesis, titulado "Exilio y Literatura", podemos percibir una clara adscripción, en una primera referencia al desconocimiento de la

\footnotetext{
2 La crítica argentina de los últimos años ha interpretado la obra de Cortázar en relación con sus opciones vitales y políticas. Un ejemplo es Ricardo Piglia, quien analiza en Crítica y ficción el ideal del artista que rompe con el mundo en algunas novelas de Cortázar, mientras que en La Argentina en pedazos se detiene en la importancia de los consumos culturales de los personajes como modo de diferenciación. En tanto, en Ficciones barrocas, a propósito de la acusación hecha a "Las puertas del cielo" de ser "un cuento reaccionario" (91), Carlos Gamerro sentencia que: "El cuento de Cortázar presenta a la vez la visión racista que los sectores 'blancos'. . . tienen de la negrada, y también objetiviza y contextualiza esa actitud, y termina mostrándola como proviniendo de un fondo de admiración y envidia, la convierte en patética" (91).

3 En Una novelita lumpen, el relato de la inmersión en la delincuencia de la protagonista, Blanca, planteada en términos de lucidez y luminosidad, es un ejemplo de ello. Sobre esto, ver mi artículo "Lo que queda de la utopía: la absolutización de la vida privada en tres relatos breves de Roberto Bolańo y Alejandro Zambra", incluido en la bibliografía.
} 
lengua extranjera: "He sido invitado para hablar del exilio. La invitación me llegó escrita en inglés y yo no sé hablar inglés. Hubo una época en que sí sabía o creía. . . que podía leer el inglés casi tan bien, o tan mal, como el español. Esa época desdichadamente ya pasó. No sé leer inglés" (2004b: 40). A partir de esta invitación, Bolaño recuerda la expatriación a que Austria obliga a su admirado amigo mexicano Mario Santiago -como hemos dicho, ficcionalización del Ulises Lima de Los detectives salvajes-y aprovecha de marcar irónicamente la distancia de ambos con la civilización europea expresada a través de la alta cultura musical: "Si Mario Santiago hubiera sido un fanático de los festivales musicales de Salzburgo, sin duda se habría marchado de Austria con lágrimas en los ojos. Pero Mario nunca fue a Salzburgo. Se montó en el tren y no bajó hasta París y tras vivir unos meses en París tomó un avión rumbo a México" (1998: 41-2). No obstante el desprecio por las sublimidades germanas, lo que Lima encuentra, una vez de regreso en el territorio latinoamericano, es la barbarie. Esta aparece en el periplo antiutópico que realiza Ulises Lima en Los detectives salvajes:

Me dijo que recorrió un río que une a México con Centroamérica. . . Un flujo constante de gente sin trabajo, de pobres y muertos de hambre, de droga y de dolor. Un río de nubes en el que había navegado durante doce meses y en cuyo curso encontró innumerables islas y poblaciones, aunque no todas las islas estaban pobladas, y en donde a veces creyó que se quedaría a vivir para siempre o moriría (1998: 367).

En su recorrido, el amigo de Belano visita dos islas, la del pasado, que se está hundiendo, y la del futuro, cuyos habitantes "probablemente acabarían comiéndose los unos a los otros" (1998: 367). El canibalismo parece ser, para el supuestamente bárbaro poeta realvisceralista, la máxima expresión del capitalismo en su tercer estadio que se enseñorea en Latinoamérica ${ }^{4}$. Más adelante veremos cómo la pobreza relacionada con este modo de producción, tal como se da en la actualidad en lugares como la frontera mexicana, es un elemento esencial del infierno en Bolaño.

En cambio, el espacio europeo, o al menos el conjunto de islas que constituyen Venecia -donde el escritor in absentia de 2666, Archimboldi, cultiva un jardín-aparece en el imaginario bolańano como un paraíso, según lo manifiesta en la última entrevista que concedió antes de morir a Mónica Maristain: "-¿Cómo es el paraíso? / -Como Venecia, espero, un lugar lleno de italianas e italianos. Un sitio que se usa y se desgasta y que sabe que nada perdura, ni el paraíso, y que eso al fin y al cabo no importa” (2004: 339).

\footnotetext{
$4 \quad$ El análisis de las representaciones de lo que Jameson llama el tercer estadio del capitalismo en su deriva informatizada y globalizada en la narrativa latinoamericana reciente es un tema de investigación muy relevante que excede los límites de este artículo. Sólo a modo de ejemplo, la figuración del capitalismo como canibalismo que se expresa en esta parte de Los detectives salvajes también está presente en la novela $E l$ año del desierto de Pedro Mairal, donde, después de que la "intemperie" ha destruido la civilización, un grupo de ejecutivos encerrados en una torre -la torre Garay, quizás en alusión al aleph de Borges que, como se sabe, se encuentra en un subterráneo de una casa de la calle Garay- se comen unos a otros. Sobre el último momento del capitalismo, ver el libro de Jameson citado en la bibliografía.
} 
De las numerosas figuraciones de este territorio de la civilización que se expresan en la obra de Bolaño me centraré en las que se presentan en dos obras póstumas, El Tercer Reich y Los sinsabores del verdadero policía, dos de cuyos personajes se han salvado del infierno latinoamericano -el Quemado y Amalfitano- y disfrutan, como el motociclista al inicio del cuento de Cortázar, de la seguridad de la ciudad moderna, y en uno de los testimonios de Los detectives salvajes. En ellas, Europa es representada como un rizoma, con las posibilidades de escape que esto conlleva, versus una Latinoamérica imaginada como un infierno-hoyo, bárbaro y letal, a la que me referiré después.

El Quemado es un joven sudamericano (2010a: 120), quizás chileno, quien sobrevive en un balneario de Cataluña arrendando patines en la playa, cuyo cuerpo y rostro están en gran parte marcados por cicatrices, como resultado, se insinúa, de la tortura (326). A pesar de su gran fuerza física, es descrito "como un conejo enorme, mortalmente asustado" (105), quien todas las noches construye un refugio con los patines que en el día arrienda, los cuales le sirven, además de medio de sustento, de resguardo. "Mitad refugio infantil, mitad chabola tercermundista” (105), afirma sobre este espacio el narrador, el joven alemán Udo Berger, quien lo describe como una fortaleza, con la estructura característica de éstas: "una estrella de puntas imprecisas" (53)5. Al ser un lugar de protección, la construcción es también una morada, que es comparada con una "madriguera de conejos", rizoma prototípico. Según Deleuze y Guattari: "las madrigueras lo son [rizomas] en todas sus funciones de hábitat, de provisión, de desplazamiento, de guarida y de ruptura" (2002: 12). Como parte de esta caracterización rizomática (lo cual, como se sabe, incluye las nociones de movimiento e inestabilidad), el Quemado debe montar su vivienda cada jornada, dándole la forma de una estrella: "La operación, tal como me la figuré aquella noche, es lenta, complicada, carente de utilidad práctica, absurda. Consiste en agrupar los patines, encarados en distintas direcciones, trabándolos entre sí hasta formar no la tradicional hilera o doble hilera sino un círculo, o mejor: una estrella” (2010a: 53) ${ }^{6}$. A sus funciones de hábitat, de acuerdo a Deleuze

\footnotetext{
$5 \quad$ La explicación que hace el especialista en arquitectura, Austerlitz, al narrador de la novela homónima de W.G. Sebald se refiere a esta forma y da además una idea del carácter rizomático que se asocia a este tipo de construcciones: "Nadie tenía hoy, dijo Austerlitz, una idea siquiera aproximada de la desmesura de la literatura sobre la construcción de fortificaciones, del carácter fantástico de los cálculos geométricos, trigonométricos y logísticos en ella recogidos y de los hipertróficos excesos del lenguaje especializado del arte de la fortificación y del asedio... aunque incluso desde nuestro punto de vista actual podemos darnos cuenta de que, hacia finales del siglo XVII, los distintos sistemas cristalizaron finalmente en el dodecágono en forma de estrella con fosos delanteros, como diseńo preferido" (2001: 18-19). La fortaleza ocupa un espacio central en las figuraciones imaginarias espaciales de la narrativa moderna, como lo muestra su importancia, en un extremo temporal, en $\mathrm{La}$ vida y las opiniones del caballero Tristram Shandy de Sterne, donde se dedica gran espacio a las fortificaciones del tío Toby, y, en el otro, en la mencionada novela de Sebald, a lo que podemos agregar la contribución de Bolańo del El Tercer Reich que comentamos.
}

6 Una definición de rizoma podría ser "multiplicidades planas de $n$ dimensiones... asignificantes y asubjetivas" (15) "que se definen por el afuera: por la línea abstracta, línea de fuga o de desterritorialización según la cual cambian de naturaleza al conectarse con otras" (2002: 14). En tanto, Deleuze y Guattari resumen así sus caracteres principales: "a diferencia de los árboles y sus raíces, el rizoma conecta cualquier punto con otro punto 
y Guattari, los rizomas agregan el ser líneas de fuga: "opciones políticas para problemas, entradas y salidas" (2002: 18), en cuyo marco se trata no "de ser libre, sino de encontrar una salida, o bien una entrada, o bien un lado, un corredor, una adyacencia” (2001: 17). Esto es lo que le permite su hogar hecho de patines al Quemado: configurar un espacio de protección en una fortaleza-rizoma y hallar una salida a la violencia latinoamericana de la que ha huido ${ }^{7}$.

cualquiera, cada uno de sus rasgos no remite necesariamente a rasgos de la misma naturaleza; el rizoma pone en juego regímenes de signos muy distintos e incluso estados de no-signos. El rizoma no se deja reducir ni a lo Uno ni a lo Múltiple. No es lo Uno que deviene dos, ni tampoco que devendría directamente tres, cuatro o cinco, etc. No es un múltiple que deriva de lo Uno, o al que lo Uno se añadiría $(n+1)$. No está hecho de unidades, sino de dimensiones, o más bien de direcciones cambiantes. No tiene ni principio ni fin, siempre tiene un medio por el que crece y desborda. Constituye multiplicidades lineales de n dimensiones, sin sujeto ni objeto, distribuibles en un plan de consistencia del que siempre se sustrae lo Uno (n-1)" (2002: 25). Varios estudiosos de la obra de Bolaño la han analizado desde una perspectiva deleuziana. Entre ellos, Pablo Catalán, quien concluye en la existencia "de dos procesos fundamentales de Arturo Belano: las fases sucesivas de un fenómeno de expansión liberadora y la integración generadora de un mundo y de un espacio-tiempo-escritura" (2003: 102). También en esta línea está el libro de Chiara Bolognese, quien piensa que los personajes de Bolaño encarnan al "nómada posmoderno" (2009: 300). Más específicamente relacionado con el tema de los desplazamientos y de la marginalidad, Felipe Ríos (2013) busca demostrar el carácter anticanónico de la literatura del escritor chileno, el que se expresa, entre otros aspectos, por el empleo de subgéneros como la ciencia ficción y el relato erótico. No obstante el interés específico de cada uno de estos trabajos, las aproximaciones de estos críticos son mucho más generales que las que presento en este artículo, en el que utilizo el pensamiento deleuziano en un ámbito muy preciso: la visión de Europa que se representa en las narraciones de Bolańo en relación a la dicotomía civilización/barbarie. En cuanto al patrón de movimiento de los personajes de Bolaño, pienso que en ningún caso se puede decir que es fijo, sino que es múltiple y rizomático. Esto queda muy claro en Los detectives salvajes, por ejemplo, en el periplo en busca de Cesárea Tinajero, donde lo que se representa es un trayecto desordenado y laberíntico, y en la dispersión que reparte a los jóvenes realvisceralistas por el mundo en la parte central de la novela. Me refiero a esto en el artículo publicado en Anales de literatura chilena que incluyo en la bibliografía. Algo en parte distinto es lo que ocurre en 2666 , en que desde una mirada inicial podría pensarse que todo confluye en Santa Teresa, una especie de hoyo negro u omphalus mundi negativo, pero en realidad los críticos regresan a Europa y, aunque es sólo una hipótesis, es probable que también lo haya hecho Archimboldi. Para quienes sí la ciudad fronteriza mexicana representa un territorio sin salida es para las jóvenes asesinadas, lo cual se vincula, desde mi lectura de Bolaño, con la dimensión material que siempre tiene la negatividad en su obra: son las más pobres entre los pobres, las mujeres obreras, las que no pueden escapar de ese centro de atracción que es Santa Teresa.

$7 \quad$ Con esto no quiero decir que se trate de una protección absoluta ni definitiva. Como se sabe, los rizomas son móviles, cambiantes, frágiles, inestables, y constituyen constelaciones del más variado carácter, compuestos por elementos - "multiplicidades"- cuya naturaleza es dispar. Esto significa que si bien su hogar de patines tiene para el Quemado en el presente de la narración un carácter protector, sobre todo si se lo compara con la violencia de su país de origen, que el lector debe imaginar, pues no es explicada en la novela, ello no representa una garantía. Lo mismo puede decirse en relación con la situación de Amalfitano que analizo a continuación: si bien la Barcelona de fines de los setenta a la que llega el profesor, luego de pasar por la tortura ni más ni menos que en Tejas Verdes, es un espacio de protección, esto no implica la inmunidad y, por lo tanto, no es una garantía para que, pasados algunos años, al verse involucrado en un escándalo sexual, deba dejar su trabajo en la universidad. 
La Barcelona de fines de los setenta y comienzos de los ochenta que se representa en Los detectives salvajes es descrita también con este potencial rizomático de protección y fuga respecto del espacio latinoamericano. Así lo es para Andrés Ramírez, el Súper Ratón de La Cisterna, quien se salva de una vida "destinada al fracaso" (1998: 83), al viajar como polizón a Europa y desembarcar en la capital de Cataluña en 1975. De inmediato, la ciudad lo acoge: "las Ramblas de Barcelona y sus calles aledañas se abrieron para mí aquella noche como los brazos de una mina que uno nunca ha visto y que sin embargo reconoce como la mina de su vida" (1998: 385). En menos de tres horas encuentra trabajo y muy pronto empieza a alucinar números con los cuales gana las quinielas. Las cifras que se le aparecen a Ramírez con una no lógica rizomática son como los patines del Quemado (¿cómo las palabras para Bolaño?): significan la posibilidad de huir de la precariedad del país de origen, de encontrar una salida, y de construir una trayectoria vital diversa de "los contornos... monstruosos con que el incierto destino se me presentaba" (1998: 384) en Chile.

A esta misma Barcelona es a la que llega el profesor Amalfitano en Los sinsabores del verdadero policía, más o menos por la misma época, después de ser "detenido y llevado a interrogar con los ojos vendados" (2010b: 42), de soportar la tortura, de haber pasado varios meses en el campo de concentración de Tejas Verdes y de practicar una vida trashumante en Buenos Aires, Brasil y México -donde tradujo La rosa ilimitada de J. M. Arcimboldi- además de Brasil, Alemania, Holanda e Italia, entre otros. Con una ironía que da cuenta de la conciencia de Bolańo respecto a los posicionamientos de los intelectuales frente a la oposición de Sarmiento, Europa es descrita como el espacio de la civilización: "descubrí lo agradable que era estar en la disidencia en un país civilizado" (2010b: 45). Pero en este nuevo espacio y, a pesar del sarcasmo, un mundo nuevo se le abre al académico latinoamericano: participa en conferencias y coloquios, "tomando aviones como si fuera un alto ejecutivo, durmiendo en hoteles de cinco estrellas, cenando en restaurantes recomendados por la guía Michelín. Todo a cuenta de contar cosas sobre la literatura" (2010b: 46). La vida diferente en la ciudad europea que, al menos en apariencia, se sacude del franquismo, con sus posibilidades desterritorializadoras, en este caso, de las identidades sexuales, lo proyecta a la homosexualidad. Así lo explica Amalfitano con una terminología en parte geopolítica:

Yo que finalmente recalé en la universidad de Barcelona, en donde me entregué a mi trabajo con entusiasmo y honestidad, yo que descubrí mi homosexualidad al mismo tiempo que los rusos descubrían su vocación capitalista, yo que fui descubierto por Joan Padilla, como quien descubre un continente, yo que fui arrastrado al delirio y redescubrí el placer y pagué por ello (2010b: 46).

Amalfitano se está refiriendo a una acusación que lo obliga a dejar su trabajo; después de lo cual la única universidad que lo recibe es la de Santa Teresa en México. Y esta es la historia que, como se sabe, se relata en la segunda parte de 2666. 


\section{Abismos latinoAmericanos}

En Los sinsabores..., la figura con la que primero se asocia al país del norte, una vez que el profesor chileno llega a vivir allí, es la barbacoa, cuya descripción, según se la imagina el personaje, permite pensar en el espacio infernal: "Amalfitano creía que en México [la barbacoa] consistía más bien en un hoyo, un hoyo cavado en el campo, preferiblemente, en donde metían brasas ardiendo, luego una capa de tierra, luego trozos de chivo, luego otra capa de tierra, y finalmente, más brasas ardiendo" (52). El hoyo en el campo, las brasas ardientes, el chivo, las capas de tierra, son todas imágenes que tradicionalmente se asocian al infierno. Con ello volvemos a recordar la entrevista citada al comienzo de este trabajo, en donde Bolaño se imagina a Ciudad Juárez, de la cual la Santa Teresa de Amalfitano es una ficcionalización, en esos términos. Así, frente a la pregunta de cómo es el infierno, responde: "Como Ciudad Juárez, que es nuestra maldición y nuestro espejo, el espejo desasosegado de nuestras frustraciones y de nuestra infame interpretación de la libertad y de nuestros deseos" (339) ${ }^{8}$.

La Santa Teresa en la que se instala Amalfitano después de su periplo rizomático por Barcelona es representada como un infierno económico, producto, en lo más evidente, de la explotación a la que son sometidas las mujeres en las maquiladoras debido al modo de producción capitalista en su tercer estadio globalizado, en los márgenes del tercer mundo. Pero también se trata de un infierno cultural, pues en la ciudad no gobiernan sólo la pobreza y la explotación material, sino que también el machismo y la violencia, y las obreras son asesinadas, podría decirse, "por nuestra infame interpretación de la libertad y de nuestros deseos". Lo anterior concuerda con la imagen de la yerbatera y vidente Florita Almada, quien visualiza a la urbe como una versión, tamizada por la industria cultural, de la ciudad dantesca del llanto y el eterno dolor: "En sueños veo los crímenes y es como si un aparato de televisión explotara y siguiera viendo, en los trocitos de la pantalla esparcidos por mi dormitorio, escenas horribles, llantos que no acaban nunca” (575).

El hoyo que, como veíamos, ha sido figurado por Bolaño con los rasgos del infierno, vuelve a surgir como representación de la Latinoamérica reencontrada por quien vuelve de Europa en Los detectives salvajes, en la última escena en que se tiene noticia de Ulises Lima. A diferencia de Belano, quien se pierde en la guerra africana de la que, no obstante, sobrevive, el poeta mexicano regresa y pronto se lo describe dando vueltas en círculos opuestos con Octavio Paz, en un Parque del DF, en cuyo nombre -Parque Hundido- la imagen reaparece. De la descripción del lugar que hace la secretaria de Octavio Paz, Clara Cabezas, podemos empezar a vislumbrar el sentido del infierno en Bolaño y también del mal, tópicos de los que tanto se ha hablado respecto a su literatura. Como queda claro en la cita siguiente, en Bolaño

\footnotetext{
8 Patricia Poblete se ha referido a la representación infernal de la ciudad fronteriza: "Santa Teresa, botón de muestra de la fealdad industrial, debe ser entendida entonces como un manifestación terrenal de un infierno o del purgatorio; el punto de fuga donde la libertad y el tedio terminan de desatarse y el mal se vuelve intersticial, inaprehensible, parte integral de la vida (pos)moderna" (41). Mi perspectiva, tal como la presento en este artículo, es muy distinta, pues pienso que el mal es muy visible en Santa Teresa, por ejemplo en las heridas infringidas a los cuerpos de las mujeres asesinadas que se describen con el mayor detalle.
} 
el infierno siempre se vincula con condiciones materiales reales y no con las dicotomías religiosas abstractas del bien y el mal": "Noté - dice- que el descuido o la desidia o la falta de medios o la más vil irresponsabilidad había deteriorado el parque hasta límites insospechables" (504); y, más adelante, "una hierba enferma de tanto ser pisoteada y que los jardineros ya ni debían cuidar" (505). O bien el infierno es una situación involuntaria que tiene que ver con la pobreza o bien es resultado de la irresponsabilidad y de la violencia humana.

Pero siguiendo con Lima, después de estos recorridos circulares que recuerdan a los de la posvanguardia descritos por $\mathrm{Paz}^{10}$, lo único que sabemos de lo que le ocurre proviene del testimonio de Daniel Grossman, en un capítulo anterior fechado en febrero de 1983, quien relata las últimas noticias que tiene del amigo de Belano: "Según algunos se había vuelto alcohólico y drogadicto. Un tipo violento al que rehuían sus amigos más cercanos. Según otros se había casado y se dedicaba a su familia a tiempo completo" (457). También se plantea la posibilidad de su muerte luego del regreso a México - "Tal vez esté muerto, dijo" (458)-, la cual se confirma respecto a su partner real, Ulises Lima, según se señala en el ensayo sobre el exilio con el que se inició este artículo. En él relata Bolaño que, luego de pasar por Austria y París, Mario Santiago volvió a su país donde "tuvo accidentes y viajó y se enamoró y tuvo hijos y vivió una vida buena o mala, una vida en todo caso en los extramuros del poder mexicano, y en 1998 un automóvil lo atropelló en circunstancias oscuras, un coche que se dio a la fuga mientras Mario se daba a la muerte" (42). El espacio en que ello ocurre es nuevamente comparado con el averno: "una calle nocturna de uno de los barrios periféricos de México Distrito Federal, una ciudad que en algún momento de su historia se asemejó al paraíso y que hoy se asemeja al infierno" (42). En este marco, su muerte como NN le parece a Bolaño "una suerte de revelación final... de epifanía negativa... como el negativo fotográfico de una epifanía, que es también la crónica cotidiana de nuestros países” (42). Se repite así la historia del migrante que regresa a la barbarie latinoamericana y que se encuentra, al igual que las mujeres de Santa Teresa, con la muerte como único destino posible.

Más adelante, en Amuleto vuelve a surgir la representación del DF como un infierno ${ }^{11}$. En un vuelo rasante, hecho al correr del DF, la palabra aparece ocho veces: cuatro relacionadas con el florero del poeta Pedro Garfias - a modo de muestra, en una de ellas se lo describe como uno de "esos objetos aparentemente tan inofensivos, [en los cuales] se ocultaba el infierno o una de sus puertas secretas" (15)-; una con las figuras de barro hechas

\footnotetext{
9 El imaginario del mal y del infierno acompaña toda la cultura occidental, desde la Biblia hasta Dante, pasando por Marlowe, Goethe, Blake, Swedenborg, Rimbaud y Bataille, entre un mar infinito de autores y textos, a los que habría que sumar, además, las visiones pertenecientes a otras culturas, como por ejemplo el Mictlán de los aztecas. Imposible sería cartografiarlo en un artículo como este. Tampoco es de mi interés, dado que, como he dicho, desde mi perspectiva, Bolaño se distancia de esta mirada y lo que representa en sus obras es la dimensión material, incluso económica, del problema.

10 "Hoy somos testigos de otra mutación: el arte moderno empieza a perder sus poderes de negación. Desde hace años sus negaciones son repeticiones rituales: la rebeldía convertida en procedimiento, la transgresión en ceremonia. La negación ha dejado de ser creadora" (463).

11 En el artículo indicado en la bibliografía, Jaime Concha se refiere al polvo que viene desde el sur del continente, desde la pampa, hasta la meseta mexicana, en términos de barbarie.
} 
por los indios que León Felipe le regala a Auxilio, que son como el antídoto del florero; una con el baño de mujeres de la UNAM, donde la uruguaya, como se sabe, pasa encerrada cuando los granaderos violan la autonomía universitaria; una con el regreso de Belano desde el Chile dictatorial -"cuando regresó al DF comenzó a salir con otros, no ya con los poetas jóvenes de México sino con gente más joven que él. . . Y luego conoció a Ulises Lima y comenzó a reírse de sus antiguos amigos. . . a mirarlo todo como si él fuera el Dante y acabara de volver del Inferno, qué digo el Dante, como si él fuera el mismísimo Virgilio" (142)-; y una con la calle Guerrero, descrita como un

río turbulento. .. similar . . a al Grijalva . . a aunque el Grijalva nocturno que era y es la avenida Guerrero había perdido desde tiempos inmemoriales su condición primigenia de inocencia. Es decir, aquel Grijalva que fluía en la noche era, bajo todos los aspectos, un río condenado por cuya corriente se deslizaban cadáveres o prospectos de cadáveres, automóviles negros que aparecían, desaparecían y volvían a aparecer. . . como si el río del infierno fuera circular, cosa que, ahora que lo pienso, probablemente sea (78).

El episodio de Amuleto en el que se presenta esta descripción es el octavo, el de "el rey de los putos", donde de nuevo se trata de un mal muy concreto, el de la esclavitud sexual a la que son sometidos algunos jóvenes por hombres poderosos ("reyes"), en este caso dos jóvenes homosexuales con nombres religiosos, uno de ellos que se encuentra al borde de la muerte -Juan de Dos (o de Dios) Montes- y otro que muere en Los detectives salvajes (Ernesto San Epifanio). Estos personajes, al igual que Ulises Lima en esta última novela, son una suerte de figuras crísticas ${ }^{12}$ que integran el memorial de las víctimas que, según Bolaño, han sido sacrificadas en lo que ha llamado "las guerras floridas" (Amuleto 76), respecto a las cuales toda su obra es algo así como una elegía ${ }^{13}$ :

los que nacimos en la década del cincuenta y los que escogimos en un momento dado el ejercicio de la... militancia, y entregamos lo poco que teníamos, lo mucho que teníamos, que era nuestra juventud, a una causa que creímos la más generosa de las causas del mundo y que en cierta forma lo era, pero que en la realidad no lo era. ... y ahora de esos jóvenes ya no queda nada, los que no murieron en Bolivia murieron en Argentina o en Perú, y los que sobrevivieron se fueron a morir a Chile o a México, y a los que no mataron allí los mataron después en Nicaragua, en Colombia, en El Salvador. Toda Latinoamérica está sembrada con los huesos de estos jóvenes olvidados (2004b: 212).

\footnotetext{
12 En mi artículo "Los detectives salvajes de Roberto Bolaño y el juicio a la vanguardia", indicado en la bibliografía, se analiza esta configuración de Ulises Lima.

13 En su "Discurso de Caracas", de recepción del Premio Rómulo Gallegos, Bolaño declara: "En gran medida todo lo que he escrito es una carta de amor o de despedida a mi propia generación” (212).
} 
Para terminar, es importante aclarar que la representación que hace Bolaño de Europa y Latinoamérica no corresponde a una dicotomía simétrica. Si bien Europa es normalmente civilizada, civilización que es motivo de burla, no está exenta de la barbarie, especialmente de la nazi, como se describe en "La parte de Archimboldi" de 2666, muy especialmente en las historia de los niños polacos alcohólicos y futbolistas que son contratados para asesinar judíos, episodio que merece un análisis aparte. Latinoamérica sí que es bárbara, si consideramos que en la narrativa de Bolaño este adjetivo se distingue de "salvaje", palabra que determina a los detectives de la novela del 98 y a otros jóvenes poetas signados positivamente en la obra de Bolaño ${ }^{14}$. Pero no siempre el arte se salva de ser bárbaro. Prueba de ello son la genealogía de escritores fascistas de la que Bolaño da cuenta en La literatura nazi en América, los montajes vanguardistas de Carlos Wieder en Estrella distante y las tertulias de María Canales en Nocturno de Chile ${ }^{15}$. La civilización como una delgada capa que al romperse, deja ver, no el pasto donde duerme el unicornio de Cortázar, sino algo así como los mataderos del siglo XXI: las calles de las megaurbes, las maquiladoras, las morgues y los basurales donde terminan los cuerpos quebrados de los jóvenes muertos, víctimas de las guerras floridas latinoamericanas y de la violencia económica del capitalismo globalizado.

\section{Obras citadas}

Areco, Macarena. 2007. "Los detectives salvajes de Roberto Bolaño y el juicio a la vanguardia". Anales de Literatura Chilena 8: 185-97.

. 2009. "Las ciudades, los tiempos, las trayectorias y los géneros de Los detectives salvajes". Anales de Literatura Chilena 11. 213-25.

. 2011. "Lo que queda de la utopía: la absolutización de la vida privada en tres relatos breves de Roberto Bolaño y Alejandro Zambra". Espejos y Prismas. Tradición y renovación en la narrativa breve moderna de España e Hispanoamérica. Actas del Coloquio Internacional organizado por el Departamento de Lengua y Literatura Españolas de la Universidad Eötvös Loránd. Ed. Mercédesz Kutasy, Gabriella Menczel y László Scholz. Budapest: Eötvös József Könyvkiadó: 7-17.

. 2017. “Civilización y barbarie en 2666”. Orillas. Rivista d'ispanistica 6: 161-169.

Baczko, Bronislaw. 2005. Los imaginarios sociales. Memorias y esperanzas colectivas. Buenos Aires: Nueva Visión.

Bolaño, Roberto. 1998. Los detectives salvajes. Barcelona, Anagrama.

1999. Amuleto. Barcelona: Anagrama. . 2004a. 2666. Barcelona. Anagrama.

\footnotetext{
14 En el artículo "Civilización y barbarie en 2666”, publicado en la revista Orillas de la Universidad de Padua, que es una suerte de continuación de este, desarrollo la distinción bárbaro/salvaje: "Un término mediador de la oposición, el adjetivo salvaje, implica un punto intermedio que, en la tradición del modernismo de Darío y Martí, remite a la literatura como una posibilidad de resistencia y autonomía” (161).

15 Sobre esto, ver el excelente artículo de López-Vicuña incluido en la bibliografía.
} 
. 2004b. "Literatura y exilio." Entre paréntesis. Barcelona: Anagrama.

. 2010a. El tercer Reich. Barcelona: Anagrama.

. 2010b. Los sinsabores del verdadero policía. Barcelona: Anagrama.

Bolognese, Chiara. 2009. Pistas de un naufragio. Cartografía de Roberto Bolaño. Santiago: Margen.

Castoriadis, Cornelius. 2007. La institución imaginaria de la sociedad. Buenos Aires: Tusquets.

Catalán, Pablo. 2003. "Los territorios de Roberto Bolaño". Territorio en fuga. Estudios críticos sobre la obra de Roberto Bolaño. Patricia Espinosa comp. Santiago: Frasis. 95-102.

Concha, Jaime. "Amuleto". 2013. Roberto Bolaño. La experiencia del abismo. Fernando Moreno ed. Santiago: ediciones Lastarria.

Cortázar, Julio. 1994. Cuentos completos 1 y 2. Madrid: Alfaguara.

Deleuze, Gilles y Félix Guattari. 2001. Kafka por una literatura menor. México: Era. . 2002. Mil mesetas. Valencia: Pre-textos.

Gamerro, Carlos. 2010. Ficciones barrocas. Una lectura de Borges, Bioy Casares, Silvina Ocampo, Cortázar, Onetti y Felisberto Hernández. Buenos Aires: Eterna cadencia.

Jameson, Fredric. 1991. El posmodernismo o la lógica cultural del capitalismo avanzado. 1984. Trad. José Luis Pardo. Barcelona, Paidós.

López-Vicuña. 2009. "Malestar en la literatura: escritura y barbarie en Estrella distante y Nocturno de Chile de Roberto Bolaño”. Revista Chilena de Literatura 75: 199-215.

Ludmer, Josefina. 2010. Aqui América Latina: una especulación. Buenos Aires: Eterna cadencia.

Mairal, Pedro. El año del desierto. Buenos Aires: Interzona, 2005.

Maristain, Mónica. 2004. "Final: 'Estrella distante' (entrevista de Mónica Maristain)”. Entre paréntesis. Barcelona: Anagrama.

Paz, Octavio. 1995. "La tradición de la ruptura". Obras Completas I. México: Fondo de Cultura Económica.

Poblete, Patricia. 2010. Bolaño: Otra vuelta de tuerca. Santiago: Universidad Academia Humanismo Cristiano.

Piglia, Ricardo. 1993. La argentina en pedazos. Buenos Aires: Ediciones de la Urraca. 2000. Critica y ficción. Buenos Aires: Planeta Argentina, 2000.

Ramos, Julio. 1989. Desencuentros de la modernidad en América Latina. Literatura y politica en el siglo XIX. México, D.F: Fondo de Cultura Económica.

Ríos, Felipe. 2013. Roberto Bolaño. Una narrativa en el margen. Valencia: Tirant humanidades.

Rojo, Grínor. 2009. “Borges, imperialismo y colonialidad: 'El Sur”. En Borgeanas. Santiago: LOM.

Sarmiento, Domingo Faustino. Facundo. Caracas: Biblioteca Ayacucho, 1977.

Sebald, W.G. 2001. Austerlitz. Barcelona: Anagrama. 